\title{
The Fontan operation, thromboembolism, and anticoagulation: A reappraisal of the single bullet theory
}

Marshall L. Jacobs, MD

See related article on page 569 .
From the Section of Cardiothoracic Surgery, St Christopher's Hospital for Children, Department of Cardiothoracic Surgery, Drexel University College of Medicine, Philadelphia, Pa.

Received for publication Sept 20, 2004; accepted for publication Sept 28, 2004.

Address for reprints: Marshall L. Jacobs, MD, St Christopher's Hospital for Children, Erie Ave at Front St, Philadelphia, PA 19134 (Email: Marshall.Jacobs@tenethealth.com).

J Thorac Cardiovasc Surg 2005;129:491-5 $0022-5223 / \$ 30.00$

Copyright $(9) 2005$ by The American Association for Thoracic Surgery

doi:10.1016/j.jtcvs.2004.09.017

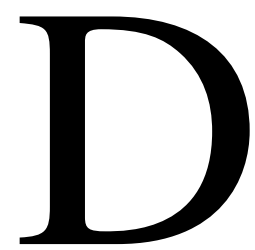

uring the more than 3 decades that have transpired since the earliest reports of "corrective surgery" for tricuspid atresia by Fontan and Baudet ${ }^{1}$ and Kreutzer and colleagues, ${ }^{2}$ the general principles of their operations have increasingly been applied to a wide spectrum of cardiovascular anomalies characterized by a functional single ventricle or nonseptatable heart. These surgical reconstructions, culminating in diversion of systemic venous return directly to the pulmonary arteries, are generally referred to as modified Fontan procedures. The earliest of these operations were technically complicated affairs with intentional implantation of valves in the venous pathways and frequent use of conduits made from various prosthetic and biologic materials. Over 30 years, the operations have evolved in a direction characterized by technical simplification of the pathways and procedures. Currently, modified Fontan procedures are really total cavopulmonary connections. The use of prosthetic materials has been minimized but not eliminated. Valves are no longer integrated into the venous pathways. The completed Fontan procedure is most often, although not always, achieved in 2 steps with a hemiFontan or superior cavopulmonary anastomosis, which is ultimately followed by a completion Fontan procedure that directs inferior caval flow to the pulmonary arteries, either entirely by extracardiac connections or by an intraatrial tunnel. The trend in operative mortality for modified Fontan procedures has been one of steady improvement from mortality rates of $25 \%$ to $30 \%$ in the earliest series to less than $5 \%$ in contemporary reports. Despite this record of progress, some factors contributing to morbidity and mortality persist. One of the major factors contributing to morbidity and failure of the Fontan circulation is the group of events referred to as thromboembolic complications. This vexing problem, and in particular the question of the potential benefit of prophylactic anticoagulant therapy in patients who undergo the Fontan operation, is the subject of ongoing controversy that challenges cardiologists, cardiothoracic surgeons, critical care physicians, and hematologists caring for this patient population. "Prophylaxis of Thromboembolic Complications After the Fontan Operation (Total Cavopulmonary Anastomosis)" is the title and subject of a retrospective review by Kaulitz and colleagues ${ }^{3}$ in this issue of the Journal. The authors review their experience with 142 survivors of modified Fontan operations, with follow-up ranging from 12 to 177 months. All operations were performed by a single surgeon, and the initial postoperative strategy for anticoagulation was based primarily on the surgical method and influenced by preoperative parameters and early postoperative functional status. Thus, 85 patients with partial prosthetic venous pathway (with or without fenestration) received acetylsalicylic acid 3 to $5 \mathrm{mg} / \mathrm{kg}$ per day. Twenty-nine other patients with partial prosthetic pathway "and uncomplicated early postoperative period" and 16 patients with autologous tissue venous pathway received no anticoagulation. Six patients received warfarin sodium (Coumadin) as initial therapy "because of borderline perioperative hemodynamic parameters or related to surgical technique." The original antithrombotic strategy was modified during follow-up when thromboembolic complications occurred or atrial arrhythmias, protein-losing enteropathy, polycythemia, or ventricular dysfunction associated with systemic venous slow blood flow phenomenon on echocardiogram developed. The authors suggested that these latter phenomena constituted circumstances associated with an increased risk of thromboembolism, 
according to their interpretation of previously published reports. Thus, in addition to 6 patients who received warfarin as primary therapy, 22 additional patients "crossed over" to warfarin on the basis of the occurrence of 1 or more of the phenomena listed, and 8 patients received heparin therapy in the setting of prolonged pleural effusions or immobilization. Using standard measures and methods of clinical follow-up, Kaulitz and colleagues ${ }^{3}$ observed thrombus formation and thromboembolic complications in 10 patients $(7 \%)$. Eight of the patients $(5.6 \%)$ presented with systemic venous thrombus formation, and 2 patients (1.4\%) presented with stroke attributed to systemic emboli. Eight of the 10 events occurred within the first year after surgery. It is interesting that of the 10 patients who had complications, 8 were receiving heparin and 1 was receiving warfarin at the time of diagnosis of the thromboembolic event. After a detailed description of their experience, the authors closed with the observation that in each instance, thrombus formation was associated with at least 1 potential predisposing factor, such as prolonged immobilization, the presence of a central venous line, protein-losing enteropathy, stenosis of the cavopulmonary anastomosis, or atrial arrhythmia. They concluded that their anticoagulation strategy, based on surgical methods and modified in the face of purported risk factors, was effective in the prevention of thromboembolic complications, and they recommended against "routine" initial anticoagulation in young children after a total cavopulmonary anastomosis.

Kaulitz and colleagues ${ }^{3}$ have thus added their experience to a steadily growing body of literature dealing with the subject of thromboembolic events and anticoagulation therapy in patients who undergo Fontan operations. The subject was highlighted in an editorial in the March 1998 issue of this Journal. In that very informative editorial, Monagle and associates ${ }^{4}$ included a then contemporary review of the literature pertaining to thromboembolism after a Fontan procedure. It revealed no prospective studies or randomized trials. The then-current literature included 35 publications, of which 15 were case reports, 4 were cross-sectional point surveys, and the remainder were retrospective series in which thromboembolism was either the primary outcome measure or one of multiple outcomes. The editorial concluded that "current practices can only be viewed as opinions based, at best, on theory and personal experiences." It called for well-controlled, prospective studies and suggested that multicenter, randomized, controlled trials comparing prophylactic antiplatelet and anticoagulation therapies were urgently required to provide rational scientific guidelines for the future management of Fontan procedures in children. In an essay titled "Thromboembolic Problems After the Fontan Operation," in the 2002 Pediatric Cardiac Surgery Annual, Monagle and $\mathrm{Karl}^{5}$ updated that literature review in an effort to represent the then contemporary body of knowledge on this complex subject. By that time, the literature included 8 retrospective cohort studies in which thromboembolic events were the primary outcome measure and 13 studies in which thromboembolic events were not the primary outcome measure, but which provided some details regarding thromboembolic events. The number of case reports grew steadily, and the additional crosssectional studies assessing thromboembolic events after Fontan procedures brought the total number of publications on this subject to 51. A detailed review of that literature led the authors to the conclusion that "despite indisputable evidence that thromboembolism following the Fontan operation is an important clinical problem, there is insufficient evidence at this time to make clear recommendations about optimal anti-coagulant prophylaxis." Once again, they called for well-controlled prospective studies. The publication ended with a brief description of the protocol for a multicenter, randomized, controlled trial comparing prophylactic antiplatelet (aspirin) with anticoagulation (heparin/ warfarin) therapy, which at the time was under way in several Australian and Canadian centers.

Earlier this year, we undertook a more contemporary review of the literature by using the methods of Monagle and Karl. ${ }^{5}$ Not included among the 51 reports analyzed by Monagle and Karl in 2002 was our cohort study, also published in 2002, ${ }^{6}$ in which low-dose aspirin prophylaxis (81 mg/day) was used consistently and exclusively as the prophylactic antithrombotic regimen in 72 consecutive young children who underwent Fontan operations in a 5 -year period. The patients had been monitored prospectively with thromboembolism as the primary outcome measure. There were no early or late deaths. Follow-up was complete with 2882 patient-months at a mean of 40 months. There were no documented thromboembolic events. All suspicious events were investigated by transesophageal echocardiography and brain imaging. There were no hemorrhagic events or aspirin-related complications. This study was unique at the time because of the consistent use of a single antithrombotic strategy in a cohort of patients followed up prospectively with evaluation for thromboembolic events as a primary end point. In addition, our updated literature search identified 21 additional studies to supplement the original list of 51 . These newer publications included 8 case reports, 1 prospective cohort study that included some details about thromboembolism among other reported outcomes, 1 prospective cohort study (with case controls) in which thromboembolism was the primary outcome measure, 7 retrospective cohort studies that included some details about thromboembolism among the reported outcomes, and 3 retrospective cohort studies in which thromboembolism was the primary outcome measure, in addition to our study, which was the only one to evaluate the consistent use of a single strategy of prophylactic medica- 
tion. What follows is a brief outline of the findings of this now-current review of the literature. Emphasis is placed on some of the more recent studies.

\section{Timing and Incidence of Thromboembolic Complications}

Monagle and Karl's review ${ }^{5}$ included 8 retrospective studies that had thromboembolic events as the primary outcome measure. The number of patients in these studies ranged from 25 to 654 , and totaled 1585 . The percentage of patients experiencing thromboses ranged from $3 \%$ to $16 \%$; the percentage of patients experiencing stroke or arterial emboli ranged from $3 \%$ to $19 \%$. In a more recent report, Coon and associates ${ }^{7}$ described the echocardiographic findings in 592 patients who underwent Fontan operations and were evaluated by echocardiography between 1987 and 1999. Fiftytwo patients $(8.8 \%)$ had intracardiac thrombus. Freedom from thrombus was $92 \%, 90 \%, 84 \%$, and $82 \%$ at $1,3,8$, and 10 years after the Fontan operation, respectively. The appearance of thrombus was not influenced by the type of operation or the presence of fenestrations. A cerebral vascular accident was documented around the time of thrombus detection on echocardiography in 8 of the 52 patients $(15 \%)$. Of the 52 patients with thrombus, 24 (46\%) were receiving aspirin, $6(12 \%)$ were receiving warfarin, and $1(2 \%)$ was receiving heparin (for protein-losing enteropathy) at the time of detection of the thrombus. A curve describing the frequency of thrombus occurrence over time closely resembled previously published curves for the development of arrhythmia and protein-losing enteropathy, leading the authors to suggest a lifelong risk of thrombus formation in patients who undergo Fontan operations and the possibility of a codependent relationship with these late complications. Seipelt and associates ${ }^{8}$ in 2002 reported that of 85 survivors of Fontan operations between 1986 and 1998, 13 (15.3\%) experienced thromboembolic events; 7 of 13 events occurred within the first postoperative year, and a second peak of frequency of events developed beyond 10 years of follow-up. The type of operation had no influence on the rate of thromboembolism. As in previous reports, there were multiple instances of thrombus detected by angiography or transesophageal echocardiography that were not clinically suspected and that were missed by transthoracic echocardiography alone. There were complex interactions between the date of operation and prophylactic anticoagulant medical regimen. Thromboembolic events occurred in patients with no anticoagulation, with aspirin therapy, and with warfarin, but a lower incidence was reported in the more recent cohort managed with warfarin. Chun and associates ${ }^{9}$ reported the incidence of stroke after Fontan procedures in 139 patients as being 3.6\% (7 strokes in 5 patients). Events occurred between 2 weeks and 9 years postoperatively. Two strokes occurred in patients receiving aspirin and warfarin, 2 strokes occurred in patients receiving aspirin alone, and 3 strokes occurred in patients receiving no anticoagulant medications.

An interesting cross-sectional study evaluating the prevalence of clinically silent pulmonary emboli in adults after Fontan operations was reported in 2003 by Varma and associates. ${ }^{10}$ All consecutive adult patients who underwent Fontan operations and were attending the clinic at the University of Toronto Congenital Cardiac Center for Adults underwent ventilation-perfusion scanning and blood testing for thrombophilic tendency. Five adult patients (17\%) had an intermediate or high probability for pulmonary embolism on ventilation-perfusion scan, all of which were confirmed on computed tomography pulmonary angiography. No patient had a thrombophilic tendency; $30 \%$ of all patients were taking warfarin because of atrial flutter or atrial fibrillation. None of them had pulmonary emboli. Older age at the time of the Fontan operation was associated with an increased risk of silent pulmonary embolism. Three contemporary studies ${ }^{11-13}$ document the increased sensitivity of transesophageal echocardiography compared with transthoracic echocardiography in the diagnosis of thromboembolic events after Fontan operations. Balling and associates ${ }^{13}$ performed a cross-sectional study of 52 patients after Fontan operations. Seventeen patients (33\%) had thrombus seen on transesophageal echocardiogram, only one of which was identified on transthoracic echocardiogram. In general, the frequency of thromboembolic events reported is increased in recent studies compared with earlier studies, and the significant incidence of clinically silent thromboembolic events is noteworthy. Improved survivals, longer durations of follow-up, improved diagnostic studies, and increased awareness of the potential for thromboembolic events are all features that undoubtedly contribute to the increase in the reporting of these events.

\section{Risk Factors for Thromboembolic Complications}

The influence of patient age at operation on the risk of thromboembolic events is unclear. In most studies, the interactions among the date of surgery, surgical methods, and use of anticoagulation regimens are complex. Most studies show no correlation between the age at surgery and the risk of thromboembolic events. Similarly, the type of Fontan operation performed, type of material used for the conduit or tunnel, and use of valved or nonvalved conduits did not appear to influence the incidence of venous thrombosis. Potentially important exceptions to these general observations are highlighted in a report by Schoof and associates $^{14}$ of thrombus development in all 3 of their patients who underwent extracardiac total cavopulmonary connection with bovine jugular vein as the extracardiac conduit. Although the incidence of thromboembolic events seems to be independent of the individual type of Fontan pathway connections, Konstantinov and associates ${ }^{15}$ described thrombosis of 
both intracardiac and extracardiac conduits after modified Fontan operations in patients with azygos continuation of the inferior vena cava. They infer that conduits carrying only hepatic venous blood may have a higher likelihood of thrombosis. Among potential hemodynamic risk factors for thromboembolic events, low cardiac output, polycythemia, arrhythmias, and right-to-left shunts have all been discussed more completely than they have been analyzed or documented as risk factors. Studies by du Plessis, ${ }^{16}$ Day, ${ }^{17}$ and their associates examined the role of fenestration with respect to strokes. Neither study found a significantly increased incidence of stroke in those patients with fenestrations.

\section{Mortality Associated With Thromboembolic Complications}

The 10 patients reported to have had thromboembolic complications after Fontan operations by Kaulitz and associates ${ }^{3}$ in this issue of the Journal appear to have survived after a variety of therapeutic interventions. In general, information on the management and outcome of thromboembolic events in patients who underwent Fontan operations is scarce and poorly documented. Monagle and $\mathrm{Karl}^{5}$ summarized the management approaches described in the literature and subsequent outcomes. Complete resolution of thrombosis was achieved in $48 \%$ of cases. Death occurred in $25 \%$ of cases, despite a variety of treatment modalities.

\section{Hematologic Factors in Patients After Fontan Operations}

Cromme-Dijkhuis and associates ${ }^{18}$ were among the first to measure coagulation factors in patients after Fontan operations. They described quantitative abnormalities involving both procoagulant and anticoagulant proteins. Approximately two thirds of patients were reported to have protein $\mathrm{C}$ deficiency at varying time intervals after Fontan operations. Deficiencies of other factor levels were reported, but they have been contested because of the absence of ageappropriate reference ranges for normal values. Jahangiri and associates ${ }^{19-21}$ contributed several reports evaluating coagulation factor abnormalities in patients who underwent Fontan operations. They confirmed deficiency of certain anticoagulant proteins such as protein $\mathrm{C}$, but also described significantly depressed levels of factor VII, a procoagulant protein. Factor VII deficiency, if moderate in degree, should predispose to bleeding, not coagulation. This, combined with the fact that protein $\mathrm{C}$ is a natural anticoagulant synthesized in the liver as a vitamin $\mathrm{K}$-dependent protein, suggests a complex interaction between procoagulant factors and anticoagulant factors in patients who undergo Fon$\tan$ operations. Odegard and colleagues ${ }^{22}$ at Harvard undertook a prospective case-control study to evaluate coagulation factor abnormalities and hemodynamic variables in pediatric patients who underwent Fontan operations. Concentrations of protein $\mathrm{C}$, factors II, V, VII, and X, plasminogen, and antithrombin III were significantly lower in patients who underwent Fontan operations compared with age-matched controls. Factor VIII was significantly elevated in 6 patients (35\%), 2 of whom had protein-losing enteropathy and thromboembolic events. A higher superior vena cava pressure was predictive of an elevated factor VIII level $(P=.003)$. No other significant hemodynamic variables were predictive of a procoagulant or anticoagulant abnormality.

\section{Comment}

Improving the outcome of Fontan operations requires a strategy to minimize the morbidity and mortality associated with thromboembolic complications. Despite a growing literature on the subject, there remain more controversies than hard facts concerning the causes and nature of these complications. There is general agreement that ligation of the main pulmonary artery, leaving a blind pouch or cul-de-sac distal to the pulmonary valve, is a worrisome substrate for the occurrence of thromboembolism. Yet, almost every other assertion that can be made with respect to thromboembolic events after Fontan operations is the subject of controversy. The influence of surgical factors and patient factors is debated. There is little agreement on the efficacy of various forms of prophylactic anticoagulant therapy. Although there has been a call for prospective, multiinstitutional, randomized trials to compare anticoagulation strategies, this is neither a simple undertaking nor one that is guaranteed to bear fruit. A principal investigator of the current Canadian-Australian multi-institutional study indicates that difficulties with the study resulted in termination of enrollment, although just one half of the targeted sample size had been achieved (personal communication, Brian W. McCrindle, September 15, 2004). One of the reasons for premature cessation of enrollment was the high frequency of protocol violations by participating patients and their caregivers. At this point, the investigators of this prospective, randomized clinical trial comparing antiplatelet prophylaxis (aspirin) with anticoagulation (heparin followed by warfarin) are analyzing the data obtained during the initial 2-year period of follow-up. Rather than anticipating a definitive conclusion as to the superiority of one or the other strategy of medical therapy, they instead are hoping that the findings of this study will ultimately lead to a more productive study design for another larger multi-institutional, randomized, prospective trial.

What do we know at this point? We know that thromboembolic events occur more frequently after modified Fon$\tan$ operations than they do after any other form of cardiac reconstruction other than prosthetic valve replacement. We know that these events occur both early and late after surgery. We know that these events contribute to the failure of the Fontan circulation and may occur with increased 
frequency in the "failing Fontan circulation." We know that thromboembolic events occur in patients receiving heparin, aspirin, or warfarin, combinations of these, or none of these. And we know, in the most general way, that the factors predisposing to thromboembolic events after Fontan operations likely represent a complex field of biologic factors with multiple interactions. As such, we are forced to acknowledge the unlikelihood that a single agent or "single bullet" will represent the solution to this challenging complex problem. We must not be discouraged by the difficulty of performing prospective, randomized clinical trials. In no instance has a prized holy grail been obtained after a quick, easy, or direct search. In the meantime, there is much to be learned from carefully reported retrospective series such as that by Kaulitz and associates ${ }^{3}$ in this issue of the Journal. They report several important observations. One is the failure of heparin to prevent or treat thromboembolic complications in the setting of adverse clinical conditions such as pathway obstruction, low cardiac output, or arrhythmias. Another is the very low incidence of thromboembolic phenomena in patients who experience a benign clinical course and are managed with either acetylsalicylic acid or no anticoagulant medication. Stratification of initial anticoagulation therapies according to surgical methods continues to be rather widely practiced, although reported data are at best inconsistent. The concept of altering anticoagulation strategy during the period of follow-up, according to the accrual of certain suspected "incremental risk factors" as practiced by Kaulitz and associates, ${ }^{3}$ seems to be worthy of consideration and further investigation.

\section{References}

1. Fontan F, Baudet E. Surgical repair of tricuspid atresia. Thorax. 1971;26:240-8.

2. Kreutzer G, Galindez E, Bono H, De Palma C, Laura JP. An operation for the correction of tricuspid atresia. J Thorac Cardiovasc Surg. 1973;66:613-21.

3. Kaulitz R, Ziemer G, Rauch R, Girisch M, Bertram H, Wessel A, et al. Prophylaxis of thromboembolic complications after the Fontan operation (total cavopulmonary anastomosis). J Thorac Cardiovasc Surg. 2005; 129:569-75.

4. Monagle P, Cochrane A, McCrindle B, Benson L, Williams W, Andrew M. Thromboembolic complications after Fontan procedures-the role of prophylactic anticoagulation. J Thorac Cardiovasc Surg. 1998; 115:493-8

5. Monagle P, Karl TR. Thromboembolic problems after the Fontan operation. Semin Thorac Cardiovasc Surg Pediatr Card Surg Annu. 2002;5:36-47.
6. Jacobs ML, Pourmoghadam KK, Geary EM, Reyes AT, Madan N, McGrath LB, et al. Fontan's operation: is aspirin enough? Is Coumadin too much? Ann Thorac Surg. 2002;73:64-8.

7. Coon PD, Rychik J, Novello RT, Ro PS, Gaynor JW, Spray TL. Thrombus formation after the Fontan operation. Ann Thorac Surg. 2001;71:1990-4.

8. Seipelt RG, Franke A, Vazquez-Jimenez JF, Hanrath P, von Bernuth G, Messmer BJ, et al. Thromboembolic complications after Fontan procedures: comparison of different therapeutic approaches. Ann Thorac Surg. 2002;74:556-63.

9. Chun DS, Schamberger MS, Flaspohler T, Turrentine MV, Brown JW, Farrell AG, et al. Incidence, outcome, and risk factors for stroke after the Fontan procedure. Am J Cardiol. 2004;93:117-9.

10. Varma C, Warr MR, Hendler AL, Paul NS, Webb GD, Therrien J. Prevalence of "silent" pulmonary emboli in adults after Fontan operation. J Am Coll Cardiol. 2003;41:2252-8.

11. Stumper O, Sutherland GR, Gueskens R, Roelandt JR, Bos E, Hess J. Transesophageal echocardiography in evaluation and management after a Fontan procedure. J Am Coll Cardiol. 1991;17:1152-60.

12. Fyfe DA, Kline CH, Sade RM, Gillette PC. Transesophageal echocardiography detects thrombus formation not identified by transthoracic echocardiography after the Fontan operation. J Am Coll Cardiol. 1991;18:1733-7.

13. Balling G, Vogt M, Kaemmerer H, Eicken A, Meisner H, Hess J. Intracardiac thrombus formation after the Fontan operation. $J$ Thorac Cardiovasc Surg. 2000;119:745-52.

14. Schoof PH, Kock AD, Hazekamp MG, Waterbolk TW, Ebels T, Dion RA. Bovine jugular vein thrombosis in the Fontan circulation. $J$ Thorac Cardiovasc Surg. 2002;124:1038-40.

15. Konstantinov IE, Puga FJ, Alexi-Meskishvilli VV. Thrombosis of intracardiac or extracardiac conduits after modified Fontan operation in patients with azygous continuation of the inferior vena cava. Ann Thorac Surg. 2001;72:1641-4.

16. du Plessis AJ, Chang AC, Wessel DL, Lock JE, Wernovsky G, Newburger JW, et al. Cerebrovascular accidents following the Fontan operation. Pediatr Neurol. 1995;12:230-6.

17. Day RW, Boyer RS, Tait VF, Ruttenberg HD. Factors associated with stroke following the Fontan procedure. Pediatr Cardiol. 1995;16: 270-5.

18. Cromme-Dijkhuis AH, Henkens CM, Bijleveld CM, Hillege HL, Bom VJ, van der Meer J. Coagulation factor abnormalities as possible thrombotic risk factors after Fontan operations. Lancet. 1990;336(8723):108790.

19. Jahangiri M, Kruetzer J, Zurakowski D, Bacha E, Jonas RA. Evaluation of hemostatic and coagulation factor abnormalities in patients undergoing the Fontan operation. J Thorac Cardiovasc Surg. 2000; 120:778-82.

20. Jahangiri M, Ross DB, Redington AN, Lincoln C, Shinebourne EA. Thromboembolism after the Fontan procedure and its modifications. Ann Thorac Surg. 1994;58:1409-13; discussion 1413-4.

21. Jahangiri M, Shore D, Kakkar V, Lincoln C, Shinebourne E. Coagulation factor abnormalities after the Fontan procedure and its modifications. J Thorac Cardiovasc Surg. 1997;113:989-93.

22. Odegard KC, McGowan FX Jr, Zurakowski D, Dinardo JA, Castro RA, del Nido PJ, et al. Procoagulant and anticoagulant factor abnormalities following the Fontan procedure: increased factor VIII may predispose to thrombosis. J Thorac Cardiovasc Surg. 2003;125:1260-7. 